\title{
Genotyping of Echinococcus granulose in Samples of Iraqi Patients
}

\author{
Dr. Maysara S. Khalf ${ }^{1}$; Dr. Mohammad A. Al -Faham ${ }^{2}$; Dr. Lazim H.Al-Taie ${ }^{3}$ \\ ; Dr. Hydar Aed Alhussian ${ }^{3}$ \\ ${ }^{1}$ Assi.lecturer College of Medical \& Health Technology. \\ ${ }^{2}$ Assit .Prof.College of Medicine /Al-Nahrain university \\ ${ }^{3}$ Assit. Prof.College of Medicine / Baghdad university.
}

\begin{abstract}
:
Background: Cystic hydatid disease is an important zoonosis, affecting humans and animals and is a significant public health and economic problem throughout the world and Iraq. Since extraction of DNA from the parasite is a primary and crucial step which has a principal effect on PCR results, in the current study five simple methods for DNA extraction from protoscoleces of Echinococcus granulosus were applied and compared with each other. The aim of study was to ascertain the genotype(s) of the parasite responsible for human hydatidosis inIraq.

Patients and Methods: After collecting hydatid cysts from patients after surgical operation, DNA samples were extracted from (60) hydatid cyst, using five different methods involving the use of glass beads, mechanical grinder, freeze-thaw, boiling and crushing. For all DNA samples extracted, one PCR assay based on amplifying rDNA-ITS1 region was performed and amplicons resolved on $2 \%$ agarose gels

For genotyping of echinoccocus $5 \mathrm{ng}$ template DNA were added into the PCR mix.

And 11 primer pair were used for genotyping .

Result: Most of the CE patients(60) patients were found to be infected with hydatid cyst of eitherG4 $26(43 \%), G 1 / G / G 3 \quad 18(30 \%), \quad G 5 \quad 12(20 \%), G 6 / G 7$ 4(7\%). And the study the association of genotypes and organ ,our results show

In the liver (20\%) Gl/G/G3, (27\%)G4,(7\%) G5, (20\%) G6/G7. Lung (7\%) Gl/G/G3,(10\%)G4,Liver and lung (3\%) Gl/G/G3 andG4, finally liver, lung and spleen (3\%) G1/G/G3.

Conclusion: These findings demonstrate the zoonotic potential of G4 (Horse strain), G1 (sheep strain) and G3 (buffalo strain), G5(Cattle Strain), (G6) (Camel Strain),(G7) (Pig strain) genotypes of E. granulosus as these emerged as predominant genotypes infecting the humans in Iraq.
\end{abstract}

Key word: Echinococcus granulosus, PCR, Germinal layer, genotypes .

\section{Introduction}

Hydatidosis/cystic echinococcosis (CE) is a severe zoonosis caused by the larval stages of a cyclophyllidean cestode called Echinococcus granulosus. Two hosts are involved in the completion of the life cycle of E. granulosus. The definitive hosts are carnivores which harbour mature tape worms in the intestine $(1,2)$. The intermediate hosts of E. granulosus include ungulates both domestic and wild animals and humans. The adult worm lives in the small intestine of carnivores (definitive host), and the intermediate larval stage (Hydatid cyst or Hydatid) develops in the internal organs of a wide range of mammalian species such as goats, sheep and cattle, including humans, which acquire the infection through accidental ingestion of the tapeworm eggs (3)

Cystic Echinococcosis is known to be one of the most important parasitic infections in livestock worldwide and one of the most widespread parasitic zoonoses $(4,5)$.

The disease has a worldwide distribution and is endemic in many countries of the Mediterranean basin, North and East Africa, Western and Central Asia, China, South America and Australia (6,7).

However, even if the distribution of Echinococcus granulosus is considered worldwide, it is higher in developing countries, especially in rural communities where there is close contact between dogs and various domestic animals (3).

In some western countries, $\mathrm{CE}$ is being considered a remergingzoonosis, due to recent increases in the observed prevalence $(8,9)$.

In humans, $\mathrm{CE}$ is the most common presentation and probably accounts for more than $95 \%$ of the estimated 2 to 3 million global cases $(10,11)$.

The echinococcosis/hydatidosis has considerable socioeconomic impact in both human and animal health in different countries (12). In humans, after a long latency period, the disease consequences may include; 
poor quality of life (disability adjusted life years [DALYS]); costs of medical treatment, lost opportunity for income generation and mortality in some cases(11) while in animals there is reduced productivity and monetary losses due to abattoir condemnations $(13,14)$. The DALYS for human CE was recently estimated to be more than that for onchocerciasis and almost the same as that for Africa trypanosomaisis(15).

Transmission and maintenance of echinococcosis is dependent on complex interactions of several factors, including environmental, host and pathogen factors. A number of such factors are of local epidemiological significance and the identification of such factors is important in the effective implementation of control strategies In Iraq, echinococcosis has been reported to occur in many parts of the country.(16,17). The "sheep" strain (defined as Gl. on mitochondrial genotypic grounds) is generally considered as the most widespread strain of E. granulosus in the world and the one mainly involved in CE in humans (Thompson and Lymbery, 1990). At least five out of ten strains of Echinococcus granulosus (G1 to G10) are infective to humans in sub- Saharan Africa (Magambo et al., 2006)

The worldwide distribution of CE reveals a geographic heterogeneity of E. granulosus species in many overlapping areas. Some examples are the co existing genotypes E. granulosus s.s. (G1) and E. canadensis (G6) in North African countries [23,30-32], E. granulosus s.s. (G1/G2), E. ortleppi (G5) and E. canadensis (G6/G7) in Argentina [20,33,34] or E. granulosus s.s. (G1), E. canadensis (G6) and E. equinus (G4) in Kyrgystan [35]. In these areas co infections with more than one E. granulosus species/genotype might occur in the intermediate or definitive hosts. In addition, the not yet confirmed hypothesis of an eventual genetic exchange by sexual reproduction between E. granulosus

species/genotypes is still discussed [36).

Extensive research on genetic variation, intermediate host affinities as well as morphological, biological and biochemical differences resulted in a more sophisticated classification of the dog tapeworm E. granulosus into ten genotypes/strains [4-6]: sheep strain (G1), Tasmanian sheep strain (G2), buffalo strain (G3), horse strain (G4), cattle strain (G5), camel strain (G6), pig strain (G7), cervid strain (G8), pig/human strain (G9) and Fenno- Scandian cervid strain (G10). The poorly characterized strain G9 is closely related to E. canadensis (G7) [7] and the existence of G9 as aseparate genotype remains still controversial [8,9].

Different methods for genotyping genetic variants of the E. granulosus complex have been developed so far. Based on PCR amplified sequences of the mitochondrial cytochrome c oxidase subunit 1 (cox1) or the NADH dehydrogenase subunit 1 (nad1),

Genotyping can be performed in a relative time and/or cost intensive way by sequencing [37], RFLP (Restriction FragmentLength Polymorphism) [38,39], fingerprinting [40] or SSCP (Single Strand Conformation Polymorphism) [41]. More recently, pure PCR based methods that simplify the genotyping have been designed. With a consecutive PCR approach a part of the E. granulosus complex (G1, G5, G6/G7) can be genotyped [42] and by applying four parallel PCRs the discrimination between E. multilocularis, E. granulosus s.s. (G1) and an E. ortleppi (G5)/E. canadensis (G6/G7) cluster is possible [30]. Parallel PCR approaches can be combined in a multiplex PCR setup and became rapidly and successfully applied worldwide in many aspects of DNA analyses, especially in the field of molecular diagnosis of infectious diseases such as bacterial [44], viral [45] and fungal [46] infections.

Parasite specimens

\section{Material and Methods}

This study was conducted in four general teaching hospitals in Baghdad governorate : Baghdad teaching hospital, Al- Shaheed Gazi Al-Hariri hospital, Liver and Digestive disease teaching hospital ,AlKadimmiya Teching Hospitals and Ibn -Al- Nafees teaching hospital, the cysts were in the liver, lung, and spleen .

In the period of this study,sixty(60) cases of space occupying lesions have been enrolled . Among these cases, 44patients were found suffering from Liver hydatidosis, 12 patients with lung hydatidosis, 2patients with liver and lung hydatidosis,2 patients with hydatid cyst on spleen,liver and lung . The diagnosis of patients was confirmed by radiological tests such as plain radiography (X-ray), Computed Tomography (C.T. scan), Ultrasound and Magnetic Resonance Imaging (MRI) .

Isolation of germinal layer of hydatid cysts:

Sixty(60) fresh fertile hydatid cysts washed several times with normal saline until the supernatant looked clear. Then, the sediment preserved in $70 \%$ ethanol until required.

Germinal layer of hydatid cyst from human will be taken after surgical operation. Samples were taken to laboratory by clean containers, sterilizing of outer surface by $70 \%$ ethanol then discarding of hydatid fluid, germinal layer would be taken and kept in ethanol $70 \%$ for different periods . 


\section{DNA extraction}

Germinal layer from Sixty(60)hydatid cyst isolates were selected. For each method, equal volumes of packed germinal layer (about50mg) were washed twice with sterile distilled water to remove ethanol. Then 300 $\mu \mathrm{l}$ lysis buffer $(\mathrm{NaCl} 0.1 \mathrm{M}$, EDTA $0.01 \mathrm{M}$, Tris- $\mathrm{HCl} 0.1 \mathrm{M}$, SDS $1 \%)$ added to each tube.

-Step two was similar for all methods:30 $\mu \mathrm{g}$ of proteinase K (Roche, Germany) was added to each tube containing samples plus $300 \mu \mathrm{l}$ lysis buffer and incubated at $56^{\circ} \mathrm{C}$ for one hour.

Then, $300 \mu \mathrm{l}$ phenolchloroform- iso amylalcohol was added and centrifuged at $5000 \mathrm{rpm}$ (2000g) for $5 \mathrm{~min}$.

After removing the supernatant to a new tube, chloroform was added prior to shaking and spanning in $5000 \mathrm{rpm}$ for $5 \mathrm{~min}$. Subsequently equal volume of iso- Propanol (Merck, Germany) and 0.1 volume sodium acetate (Merck, Germany) (3M, pH=5.2) were added to the supernatant, and kept at $-20{ }^{\circ} \mathrm{C}$ for $20 \mathrm{~min}$. Next, it was spun $12 \mathrm{~min}$ in $12000 \mathrm{rpm}$ and the sediment was rinsed by $300 \mu 170 \%$ ethanol. After spinning $5 \mathrm{~min}$ in $5000 \mathrm{rpm}(2000 \mathrm{~g})$ and removing ethanol, pellet was dissolved in $50 \mu \mathrm{l}$ deionized water, and stored at $-20^{\circ} \mathrm{C}$ for PCR process.

mPCR conditions:

The reaction mix for the final $\mathrm{mPCR}$ was composed of $100 \mathrm{mM}$ dNTPs and 0.05 units $\mathrm{ml} 21 \mathrm{GoTaq}$ DNA polymerase in 16PCR Buffer (all Promega) and contained the 22 primers specific for 11 targets in the molarities shown in Table 1. For standard genotyping $5 \mathrm{ng}$ template DNA were added into the PCR mix.

Each reaction was performed in single tubes in a volume of $20 \mathrm{ml} \mathrm{PCR} \mathrm{mix.} \mathrm{The} \mathrm{cycling} \mathrm{conditions}$ were as follows: an initial denaturation step at $94 \mathrm{uC}$ for $3 \mathrm{~min}, 25$ cycles $\left(94^{\circ} \mathrm{C}-30 \mathrm{~s}, 56^{\circ} \mathrm{C}-30 \mathrm{~s}, 72 \mathrm{C}-1 \mathrm{~min}\right)$ and a final extension step lasting $5 \mathrm{~min}$ at $72 \mathrm{uC} .10 \mathrm{ml}$ of the PCRs were separated by electrophoresis in a $2 \%$ agarose gel and visualized by red safe staining and subsequent UV excitation. The genotype specific amplicon profile is shown in Figure 1.

\section{Results:}

Table (1) : Measurment ofDNA Concentration by Using Scan Drop Methods:

\begin{tabular}{|l|l|l|l|}
\hline Methods & Without correction & Withcorrection & Unit \\
\hline DNA detection & 1.77 & 2.71 & $\mathrm{~A}$ \\
\hline DNA purity & 1.33 & 1.89 & \\
\hline Ratio230/260 & 32.45 & 9.88 & \\
\hline Ratio260/230 & 0.03 & 0.10 & \\
\hline dsDNA concetration & 38.29 & 135.53 & $\mathrm{Ng} / \mu 1$ \\
\hline ssDNA concentration & 25.27 & 89.45 & $\mathrm{Ng} / \mu 1$ \\
\hline RNAconcentration & 30.63 & 108.42 & $\mathrm{Ng} / \mu 1$ \\
\hline
\end{tabular}

Table (2): Genotypes of E. granulosus in Samples of Iraqi Patients

\begin{tabular}{|c|c|c|c|c|}
\hline Genotypes & Product size/bp & Gene marker & No.of + cases & Percentage \\
\hline G1/G/G3 & $706 \mathrm{bp}$ & Ef1a & 16 & 26.6 \\
\hline G1/G/G3 & $1001 \mathrm{bp}$ & Cal & 2 & 3.3 \\
\hline G4 & $124 \mathrm{bp}$ & Cox 1 & 26 & 43.3 \\
\hline G5 & $1041 \mathrm{bp}$ & Atp-6 & 4 & 6.6 \\
\hline G6/G7 & 339 bp & Nad1 & 4 & 6.6 \\
\hline G6/G7 & 617 bp & Pold & 8 & 13.3 \\
\hline Total & & & 60 & 99.7 \\
\hline
\end{tabular}

Table (3): The prevalence of Hydatid cyst Genotypes in the Infected Organs

\begin{tabular}{|c|c|c|c|c|c|}
\hline Organ & Genotypes & Gene marker & Product size/bp & No. of + cases & Percentage (\%) \\
\hline \multirow[t]{6}{*}{ Liver } & G1/G/G3 & Ef1a & 706 & 10 & 16.6 \\
\hline & G4 & Cox 1 & 124 & 16 & 26.6 \\
\hline & G1/G/G3 & Cal & 1001 & 2 & 3.3 \\
\hline & G5 & Atp-6 & 1041 & 4 & 6.6 \\
\hline & G6/G7 & Pold & 617 & 8 & 13.3 \\
\hline & G6/G7 & Nad1 & 339 & 4 & 6.6 \\
\hline \multirow[t]{2}{*}{ Lung } & G1/G/G3 & Ef1a & 706 & 4 & 6.6 \\
\hline & G4 & Cox 1 & 124 & 6 & 10 \\
\hline \multirow[t]{2}{*}{ Liver+lung } & G1/G/G3 & Ef1a & 706 & 2 & 3.3 \\
\hline & G4 & Cox1 & 124 & 2 & 3.3 \\
\hline Liver+lung+spleen & G4 & Cox 1 & 124 & 2 & 3.3 \\
\hline Total & & & & 60 & $99.5 \%$ \\
\hline
\end{tabular}


Genotyping of Echinococcus granulose in Samples of Iraqi Patients

Table (4): The Genotype Distribution of Hydatid Cyst In The Infected Organs

\begin{tabular}{|l|l|l|l|l|l|l|l|l|}
\hline & \multicolumn{2}{|l}{ G1/G/G3 } & G4 & G5 & G6/G7 \\
\hline & Count & Percent & Count & Percent & Count & Percent & Count & Percent \\
\hline Liver & 12 & $20 \%$ & 16 & $27 \%$ & 4 & $7 \%$ & 12 & $20 \%$ \\
\hline Lung & 4 & $7 \%$ & 6 & $10 \%$ & 0 & $0 \%$ & 0 & $0 \%$ \\
\hline Liver+lung & 2 & $3 \%$ & 2 & $3 \%$ & 0 & $0 \%$ & 0 & $0 \%$ \\
\hline $\begin{array}{l}\text { Liver+lung+splee } \\
\mathrm{n}\end{array}$ & 2 & $3 \%$ & 0 & $0 \%$ & 0 & $0 \%$ & 0 & $0 \%$ \\
\hline
\end{tabular}

\section{Discussion:}

E chinococcus granulosus and its metacestode in herbivores and humans have been recognized as the most important helminthes zoonoses, with great economic and public health significances in developing countries(1). Hydatidosis is endemic in the entire Mediterranean zone including all Middle Eastern countries (2).

The highest risk group in the country is specifically in Arab Gulf region -in general- which are women and children. Traditionally, rural women still bear the biggest burden of tending animals - whether breeding, milking, or wool shearing- and domestic or stray dogs are never faraway. The added chore of women preparing and cooking contaminated food and vegetables with little clean water at hand increases considerably the risk of infection. In many parts of Middle East during springtime, it is common practice together berries and various wild plants which are eaten unwashed and geophagia among children and pregnant women is well known(2).

But the domestic dog as a definitive host for E. granulosus plays an important role in the spread of infection in the Middle East countries via contamination of environment. Sheep, goats, cattle, camels, buffaloes, pigs, and donkeys have been repeatedly found infected with hydatid cysts in Iran, Iraq,Jordan, Lebanon, Syria, Kuwait, and Saudi Arabia (311).

PCR was used as a suitable tool for the characterization of E. granulosus strains in different studies. The success in PCR depends on the quantity and quality of the extracted DNA. There are some comparative studies of different DNA extraction methods forganisms, such as fungi, bacteria, viruses and protozoa (14-18).

The liver act as the first filter for larval infection and the lung acts as the second filter. Distribution of infection in different organs showed that the liver was the most frequently involved $44(73.3 \%)$ when compared with lung $12(20 \%)$ and liver and lung 2(3.3\%) and other multiple infected organs such asliver ,lung and spleen2(3.3\%) Table 3, generally these proportions approximately in agreement with most of previously recorded data by Ahmadi and Al-Dalimi (2006) (28) .

Genotyping of human cases of CE play an important role in the formulation of control strategies for the prevention of transmission of this parasite.

Strain variation in parasites exhibit variation in the onset of egg production, which is a limiting factor in control programs, which employs adult cysticidial treatment of definitive host to break the cycle of transmission [24]. Further it is postulated that the strain variation in parasite may influence host specificity, lifecycle patterns, development rate, transmission dynamics, antigenicity and sensitivity to chemotherapeutic agents. Therefore it may have implications for the development and design of vaccines and diagnostic reagents [4).

Abdulla etal.,2012 reported G1(sheep strain ) recorded in Kurdistan Iraq and there is no adequate study on genotyping of echinococcosis in Iraq.

In Iraq , 26(43\%) G4, $18(30 \%) \mathrm{G} 1 / \mathrm{G} / \mathrm{G} 3$ were found the commonly encounter ered in Iraqi patients while $4(6.6 \%) \mathrm{G} 5$, and 4(6.6\%) G6/G7. Genotype of infecting strain affects the fertility rate of the cysts in the intermediate hosts and thereby the infectivity of strain for the subsequent hosts in the table (4-10), the present findings, study the association between echinococcus genotypes and related organ, the current study shows 26(43\%) G4 (Horse Strain), 18(30\%) G1/G/G3 (sheep strain), 4(7\%) G6/G7 (camel and pig strain), 12(20\%) G5 (cattle strain).

Our results in agreement with other studies by (Elizabeth et al., 2010; Abdullah et al., 2012; Sharma et al., 2013). And disagreement with Ergin et al., (2010); Boubaker et al., (2013).

In addition, the association between genotype and various organ, our finding in the table (4-11) included the following criteria.

In the liver involved 12(20\%) G1/G/G3 (sheep strain), 16(27\%) G4 (horse strain), 4(7\%) G6/G7 (camel and pig strain), and 12(20\%) G5 (cattle strain). In the lung 2(3\%) G4 (horse strain).

Moreover, the relation between genotype and multiple organ infection liver and lung, our results showed $2(3 \%)$ G1/G/G3 (sheep strain) 2(3\%) G4 (horse strain) in the liver, lung and spleen. Our finding shows 4(7\%) G1/G/G3 sheep strain, 6(107\%) G4 horse strain, the total genotypes were recorded in the various organ included the following, 18(30\%) were G1/G/G3, 26(43\%) were G4, 4(7\%) were G6/G7 and finally 12(20\%) were G5, these results were statistically not significant ( $>0.05)$, and in agreement with Sharmal et al.,(2013). In table (4-14), our finding, were shows the gene maker distribution anhydrate cyst patients genotypes as he follows: $16(26 \%)$ were EF1a (796bp) gene, (2,3\%) were CaL (1001bp) gene, while 26(43\%) Cox1(124bp) gene, 4(6.61) were ATP-6(1041 bp) gene, 4(6.6\%) were Nad1, (339bp) gene, 8(13\%) were pold (617bp) gene. These finding in agreement with Sharma et al., (2013); and disagreement Ergin et al.,(2010); Khder et al.;(2013). 


\section{References}

[1]. Zhang, W., Li, J. \& McManus, D. P. Concepts in immunology and diagnosis of hydatid disease.Clin Microbiol Rev, . (2003) 16, 18-36.

[2]. Khuroo, M. S. Hydatid disease: current status and recent advances. Annals of Saudi Medicine, (2002). 22, 56-64.

[3]. Eckert, J. \& Deplazes, P. Biological, epidemiological, and clinical aspects of echinococcosis, a zoonosis of increasing concern. Clinical Microbiology Review, (2004) 17, 107-35.

[4]. Craig, P. S., Rogan, M. T. \& Allan, J. C. Detection, screening and community epidemiology of taeniid cestode zoonoses: cystic echinococcosis, alveolar echinococcosis and neurocysticercosis. Advances in Parasitology, (1996). 38, 169-250.

[5]. Cabrera, P. A., Lloyd, S., Haran, G., Pineyro, L., Parietti, S., Gemmell, M. A., Correa, O., Morana, A. \& Valledor, S. Control of Echinococcus granulosus in Uruguay: evaluation of different treatment intervals for dogs. Veterinary Parasitology, . (2002), 103, 333-40.

[6]. Jenkins, D. J. Hydatid control in Australia: where it began, what we have achieved and where to from here. International Journal of Parasitology, (2005). 35, 733-40.

[7]. Romig, T., Thomas, D. \& Weible, A. K. Echinococcus multilocularis - a zoonosis of anthropogenic environments? Journal of Helminthology, (2006) 80, 207-12.

[8]. Himsworth, C. G., Jenkins, E., Hill, J. E., Nsungu, M., Ndao, M., Andrew Thompson, R. C., Covacin, C., Ash, A., Wagner, B. A., Mcconnell, A., Leighton, F. A. \& Skinner, S. Emergence of sylvatic Echinococcus granulosus as a parasitic zoonosis of public health concern in an indigenous community in Canada. American Journal Tropical Medicine Hygiene, (2010) 82, 643-5.

[9]. Budke, C. M., Campos-Ponce, M., Qian, W. \& Torgerson, P. R. A canine purgation study and risk factor analysis for echinococcosis in a high endemic region of the Tibetan plateau. Veterinary Parasitolology, (2005). 127, 43-49.

[10]. Craig, P. S., Rogan, M. T. \& Allan, J. C. Detection, screening and community epidemiology of taeniid cestode zoonoses: cystic echinococcosis, alveolar echinococcosis and neurocysticercosis. Advances in Parasitology, (1996). 38, 169-250.

[11]. Budke, C. M., Deplazes, P. \& Torgerson, P. R. Global socioeconomic impact of cystic echinococcosis. Emerging Infectious Diseases, (2006). 12, 296-303.

[12]. Rkia Azlaf, A. D. Epidemiological study of the cystic echinococcosis in Morocco. Veterinary Parasitology, (2006) 137, 83-93.

[13]. Torgerson, P. R. \& Heath, D. D. Transmission dynamics and control options for Echinococcus granulosus. Parasitology, (2003) 127 Suppl, S143-58.

[14]. Scala, A., Garippa, G., Varcasia, A., Tranquillo, V. M. \& Genchi, C. Cystic echinococcosis in slaughtered sheep in Sardinia (Italy). Veterinary Parasitology, (2006) 135, 33-8.

[15]. Budke, C. M., Deplazes, P. \& Torgerson, P. R. Global socioeconomic impact of cystic echinococcosis. Emerging Infectious Diseases, (2006). 12, 296-303

[16]. Ihsan E. Al-Saimary, Maani N. Al-Shemar, and Mohammed M. A. Al-FayadhEpidemiological and immunological findings on human Hydatidosis. ,(2010) Vol. 1(2), pp. 26-34, November 2010. Medical Practice and Review

[17]. Mahdi M. Bajalan:" Prevalence of echinococcus in stary dog and slaughtered livestock Kalar district/Sulaimaniya province /Kurdistan Iraq",MSc.thesis ,College of veterinary medicine ,University of Baghdad (2006).

[18]. Lemu Golassa, Tamrat Abebe and Asrat Hailu.(2010). Evaluation of crude hydatid cyst fluidantigens for the serological diagnosis of hydatidosis in cattle. Department o Medical Laboratory Sciences and Pathology, College of Public Health and Medical Sciences, Jimma University, PO Box 378, Jimma,Ethiopia: Microbiology, Immunology and Parasitology Department,Medical Faculty, Addis Ababa University, PO Box 9086, Addis Ababa,Ethiopia.

[19]. Muller R. Worms and human diseases. 2nd ed. Wallingord: CABI International, Oxon, UK; 2002.

[20]. Sadjjadi SM. Present situation of echinococcosis in the Middle East and Arabic North Africa. Parasitol Int. 2006;55 Suppl:S197-202

[21]. Abdul-Karim H. Hydatid disease of the liver and its biliary communication. Iraq. J. Med. Sci., (2001). 1: 200-203.

[22]. Al-Qadhi BN. Study of some immunological and biochemical aspects of patients infected with hydatidosis . Ph.D. Thesis. College of Science, University of Baghdad (2005).

[23]. Nakao M, McManus DP, Schantz PM, Craig PS, Ito AA. Molecular phylogeny of the genus Echinococcus inferred from complete mitochondrial genomes. Parasitology, (2007).134: 713-722

[24]. Brunetti E, Gulizia R, Garlaschelli AL, Filice C. Cystic Echinococcosis of the liver associated with repeated international travels to endemic areas. J. Travel. Med., (2005).12(4): 225-228.

[25]. Torgerson, P. R. \& Heath, D. D. Transmission dynamics and control options for Echinococcus granulosus. Parasitology, (2003). 127 Suppl, S143-58.

[26]. Fakhar M, Sadjjadi SM. Prevalence of hydatidosis in slaughtered herbivores in Qom Province, central part of Iran. Veterinary Research Communications. (2007);31(8):993- 997.

[27]. Daryani A, Alaei R, Arab R, Sharif M, Dehghan MH, Ziaei H. The prevalence, intensity and viabilitymof hydatid cysts in slaughtered animals in the Ardabil Province of Northwest Iran. J Helminthol.; (2007) . 81:13-17.

[28]. 28: Ahmadi NA. Hydatidosis in camels (Camelus dromedarius) and their potential role in the epidemiology of Echinococcus granulosus in Iran. J Helminthol.; (2005 ),79(2):119-25.

[29]. Rokni MB. The present status of human helminthic diseases in Iran. Ann Trop Med Parasitol. (2008) ,1

[30]. Abebe, F. and J. Yilma, 2011. Infection Prevalence of Hydatidosis (E. granulosus, Batsch, 1786) in Domestic Animals in Ethiopia: A synthesis report of previous surveys. Ethiopian Veterinary Journal, 15: 11-33.

[31]. Dawit, G., F. Aklilu, T. Gebregergs, A. Hasen and T. Ykealo, 2013. Knowledge, Attitude and Practices of Hydatidosis in Pastoral Community with Relation to Public Health Risks in Ayssaita, Northeastern of Ethiopia. Global Veterinaria, 11(3): 272-279.

[32]. Casulli, A., E. Zeyhle, E. Brunetti, E. Pozio, V. Meroni, F. Genco and C. Filic, 2010. Molecular evidence of the camel strain (G6 genotype) of E. granulosus in humans from Turkana, Kenya. Transaction of Royal Society of Tropical Medicine and Hygiene, 104: 29-32.

[33]. Parsaei, P., M. Mohammad, O. Anari, M. Riahi and E. Rahimi, 2012. Prevalence of Hydatidosis in Slaughtered Animals of South West of Iran. Global Veterinaria, 9(4): 430-433.

[34]. Fathi, S., M.D. Mirzaei and M.H. Radfar, 2012. Occurrence of hydatidosis in camels (Camelus dromedarius) and their potential role in the epidemiology of E. granulosus in Kerman area, Southeast of Iran. Competency of Clinical Pathology, 21: 921-927.

[35]. Abebe, F. and J. Yilma, 2011. Infection Prevalence of Hydatidosis (E. granulosus, Batsch, 1786) in Domestic Animals in Ethiopia: A synthesis report of previous surveys. Ethiopian Veterinary Journal, 15: 11-33.

[36]. Ergin S. ;Saribas S.;Yuksel P.;Zengin K.;etal (2010).Genotypic characterization of Echinococcus granulosus isolated from human in Turky .African J.Micro.Resch.vol4(7),pp.551-555. 